\title{
Single application of high-intensity focused ultrasound (HIFU) in clinically localized prostate cancer- Late oncological results and comparative cancer control efficacy with different HIFU device generations
}

\author{
Pfeiffer $\mathrm{D}^{1 *}$ and Berger $\mathrm{J}^{2}$ \\ ${ }^{1}$ Dept. of Urology, Asklepios Westklinikum Hamburg, Germany \\ ${ }^{2}$ Center of Experimental Medicine, Institute of Medical Biometry and Epidemiology, University Hospital Hamburg-Eppendorf, Germany
}

\begin{abstract}
Purpose: To report late oncological outcomes in men with localized T1-T3 prostate cancer following single-session HIFU performed under the conception of wholegland therapy.

Material and methods: This retrospective single-center study enrolled patients, who were uniformly treated by whole-gland ablation between December 2002 and September 2012. Treatment involved two generations of Ablatherm devices, the Maxis (A1) and the Integrated Imaging (A2). Outcome measures were overall survival, cancer-specific, metastasis-free, biochemical-free, and disease-free survival. Biochemical failure was assessed using PSA nadir +2 and nadir +1.2 failure definitions. Disease failure was defined as positive control biopsy and/or PSA failure (nadir $+2 \mathrm{ng} / \mathrm{ml}$ ). Kaplan-Meier analyses were performed for survival estimates. Multivariate analysis was performed using Cox models.

Results: Of 357 study patients, 146 (40.9\%), 124 (34.7\%) and 87 (24.4\%) exhibited low-, intermediate- and high-risk disease (D'Amico), respectively. Median patient age was 70 yrs. Median follow-up was 6.5 yrs. (interquartile range, 4.3-8.9). The 10-year overall, cancer-specific and metastasis-free survival rates were $68 \%, 95 \%$ and $91 \%$, respectively. The 8-year biochemical-free survival rates according to risk grouping were $93 \%, 76 \%$ and $48 \%$, or $81 \%, 62 \%$ and $45 \%$ for nadir +2 and nadir +1.2 failure definitions. The 8-year disease-free survival (DFS) rates were $76 \%, 49 \%$ and $42 \%$, respectively. 8-year estimates of DFS differed between the HIFU-devices $\mathrm{A} 1$ and $\mathrm{A} 2$ (54\% vs. $74 \%, \mathrm{p}<.001)$. The device generation predicted disease failure (hazard ratio .51, $\mathrm{p}=.001)$ independent from risk group, pre-treatment PSA level and Gleason sum.
\end{abstract}

Conclusions: Success with single-session HIFU does not depend solely on tumor determinants. Ablation is more efficacious with the technically advanced A2 HIFU device.

\begin{abstract}
Abbreviations: ADT: Androgen deprivation therapy; AS: Active surveillance; ASA: American society of anaesthesiologists; BFS: Biochemical failure-free survival; DFS: Disease-free survival; HIFU: High-intensity focused ultrasound; HR: Hazard risk; IMRT: Intensity-modulated radiation therapy; IQR: Interquartile range; MFS: Metastasis-free survival; PCa: Prostate cancer; PCSS: Prostate cancer specific survival; RT: Radiotherapy.
\end{abstract}

\section{Introduction}

High-intensity focused ultrasound (HIFU) ablates the prostate in situ. The curative potential for the treatment of localized prostate cancer $(\mathrm{PCa})$ was already recognized in the 1990s [1,2] subsequently, the use of HIFU therapy expanded to include the treatment of localized PCa with high risk of tumor progression $[3,4]$. In Europe, extensive experience has been gained using Ablatherm HIFU devices (EDAPTMS, Vaulx-en-Velin, France). Recent reports on late outcomes show that cancer control rates following HIFU are associated with the risk groups of tumor recurrence (D'Amico [5]), suggesting a strong impact of tumor determinants on oncological results [6-8]. However, these reports included repeat HIFU treatment, with a mean of 1.2 to $1.4 \mathrm{HIFU}$ treatments per patient, which confounds the interpretation of HIFU efficacy and raises the question whether the initial tumor ablation was performed adequately on all patients.

Under-treatment of PCa due to an inadequate HIFU approach was addressed by Blana et al. who marked the significance of complete prostate ablation as a prerequisite of tumor eradication; whole-gland therapy requires that all parts of the gland are exposed to the traversing ultrasound and ablation should avoid leaving gaps of untreated tissue [9]. The ability to treat the entire gland may also be influenced by the technical standard of the apparatus. Recent studies involved different commercially available HIFU device generations and even prototypes. The most important factor was the lack of visual real-time control of the on-going procedure until $2005[10,11]$, leaving a risk of undertreatment due to discrepancies between plan and performance.

${ }^{*}$ Correspondence to: Dietrich Pfeiffer, Department of Urology, Asklepios Westklinikum Rissen, Suurheid 20, D - 22559 Hamburg / Germany, Tel: 4940 8191 4417; E-mail: d.pfeiffer@asklepios.com

Received: January 15, 2021; Accepted: January 25, 2021; Published: February 08,2021 
Pfeiffer D (2021) Single application of high-intensity focused ultrasound (HIFU) in clinically localized prostate cancer- Late oncological results and comparative cancer control efficacy with different HIFU device generations

In the present study, we evaluated the late oncological efficacy with HIFU following single-session whole-gland ablation for localized PCa. Two generations of Ablatherm devices were involved. The study focused on oncological outcomes, whereas treatment-related morbidity had already been reported elsewhere [12].

\section{Patients and methods}

This retrospective single-center study enrolled patients with clinically localized PCa who underwent a single session of wholegland HIFU treatment as a first-line therapy with curative intent at the Asklepios Clinic Hamburg-Barmbek between December 2002 and September 2012. All men were unsuitable candidates for radical prostatectomy due to age or comorbidity and were unwilling to undergo radiotherapy $(\mathrm{RT})$.

Patients were stratified into risk categories of tumor recurrence according to D'Amico [5]. Criteria for the high-risk category were modified to include patients with tumor stage cT3 (TNM 2002). Extracapsular tumor extension and lymph node status was assessed with CT or MRI. Staging included bone scans in men with PSA $\geq 10$ $\mathrm{ng} / \mathrm{ml}$. Patients with apical prostate tumor or metastases were not considered for local HIFU treatment.

Excluded from the study were men who received organ-preserving HIFU ablation (treating only parts of the gland [13]). Patients on androgen deprivation therapy (ADT) were not excluded. ADT was discontinued at the time of HIFU therapy.

One operator (D.P.) conducted $94 \%$ of all HIFU procedures. Treatment involved the use of two commercially available Ablatherm devices, the Maxis device and (after February 2006) the Integrated Imaging device, hereafter addressed respectively as devices A1 and A2. The A2-device allowed for the more precise targeting of the prostate and TRUS-based visual real-time control of the ongoing procedure $[10,11]$.

The intention of whole-gland treatment is the destruction of the prostate with a safety margin of $6 \mathrm{~mm}$ from the apex to preserve the urethral sphincter. Our ablation technique included an overlap of treatment zones to avoid leaving gaps of untreated tissue [9]. With enlarged glands, anterior margins were ablated with a second pass. Glands with an excess in height ( $>2.6 \mathrm{~cm}$ [TRUS]) required prostate resection prior to HIFU to adjust the gland size to the limited penetration depth of the ultrasound beam (approximately $30 \mathrm{~mm}$ ).

Postoperative follow-up included serial PSA measurements. Control biopsies were recommended after 6 months and in cases of rising PSA. The metastatic status was assessed in case of a PSA doubling time $\leq 6$ months. Follow-up data were obtained by periodical patient contacts or medical records. Cause of death was identified from physician correspondence. The data were collected in an Access database (prospectively established in 2002). The use of prospectively collected data for outcome evaluations was approved by the local ethics committee.

Outcome measures were overall survival (OS), prostate cancerspecific survival (PCSS), biochemical failure-free survival (BFS), disease-free survival (DFS) and metastasis-free survival (MFS). Biochemical failure was defined according to the ASTRO Phoenix definition (PSA nadir $+2 \mathrm{ng} / \mathrm{ml}$ [14]) and the Stuttgart definition (PSA nadir $+1.2 \mathrm{ng} / \mathrm{ml}$ [15]). Disease failure was expressed as positive biopsy and/or biochemical relapse (nadir+2 definition), whichever occurred first. The type and sequence of salvage treatment was also recorded.
Statistical analysis was performed using StataSE v.13 (StataCorp LP, College Station, USA). Categorical variables were compared using Fisher's exact test. Quantitative variables were compared with the Mann-Whitney-U-test. The Kaplan-Meier method was used to construct survival curves, which were compared using the log-rank test. The Cox regression model was used to estimate the prognostic relevance of different variables on disease failure. The follow-up period was defined as the interval between HIFU treatment and the last available monitoring data or the date of death. Median (IQR) follow-up time was established with the inverse Kaplan-Meier method. A p-value $<0.05$ was considered statistically different.

\section{Results}

A total of 357 patients aged 55 to 82 years were enrolled in the study. According to the ASA risk classification, 129 (36.1\%) men exhibited an elevated perioperative risk (ASA III-IV). HIFU was delivered with the A1-device in 139 patients, and the A2-device in 218 patients. Baseline characteristics are summarized in Table 1. Most patients underwent prostate surgery prior to HIFU, either for BPH (resulting in incidental carcinoma) or synchronously with HIFU Procedures were TURP $(n=281)$, adenomectomy $(n=7)$, or laser enucleation $(n=5)$. Prior to HIFU, 112 (31.6\%) men received ADT for median (IQR) 10 (6-24) weeks. Treatment characteristics are summarized in Table 2. The prostate size (pre-plan) allowed for complete HIFU ablation in all but 5 (1.4\%) glands which exhibited an excess in height, thereby limiting the ablation of anterior margins. With both devices, the ablation technique was similarly extensive; the treatment volume exceeded the measured prostate volume (pre-plan) by factor 2.1 (mean 2.2).

\section{Survival}

Median (interquartile range [IQR]) follow-up was 6.5 (4.3-8.9) years (95th percentile:10.5). The vital status was evaluable for 356 (99.7\%) men. The 10-year OS-rate was 68\%(95\%-CI,58-76\%) (Figure 1). Patients aged $>75$ years were more likely to die than those aged 55 to 65 years (hazard ratio [HR], 2.32 [95\%-CI,1.33-4.10], $\mathrm{p}=0.003$ ). Amongst the oldest men, the risk of death was associated with an elevated perioperative risk (ASA III-IV) at the time of HIFU (HR, 2.72 [95\%-CI,1.34-5.47], $\mathrm{p}=.005)$.

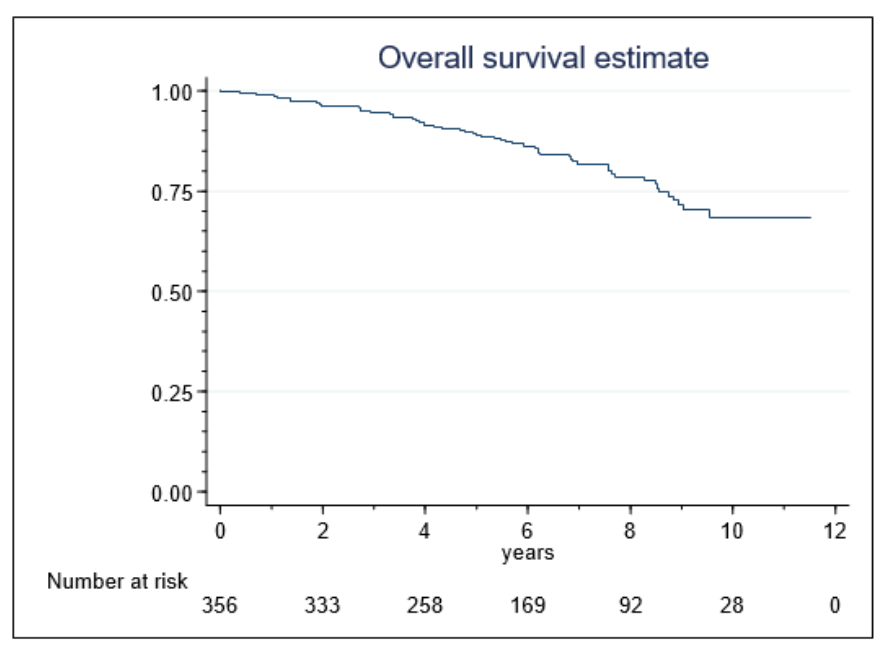

Figure 1. Overall survival in 356 patients following single-session HIFU treatment of localized prostate cance 
Pfeiffer D (2021) Single application of high-intensity focused ultrasound (HIFU) in clinically localized prostate cancer- Late oncological results and comparative cancer control efficacy with different HIFU device generations

Table 1. Baseline characteristics in 357 patients and in subgroups by Ablatherm HIFU devices

\begin{tabular}{|c|c|c|c|c|}
\hline & \multirow[t]{2}{*}{ Total } & \multicolumn{2}{|c|}{ Ablatherm HIFU devices } & \multirow[t]{2}{*}{ p value } \\
\hline & & Device A1* & Device A2* & \\
\hline Patients N (100\%) & 357 & 139 & 218 & \\
\hline Age (yrs.) & $70(66-74)$ & $71(66.5-75)$ & $70(66-74)$ & .20 \\
\hline PSA at diagnosis (ng/mL) & $7.2(5.0-10.9)$ & $7.2(4.8-13.2)$ & $7.2(5.1-10.4)$ & .53 \\
\hline Gleason sum & & & & .107 \\
\hline$\leq 6$ & $221(61.9)$ & $90(64.7)$ & $131(60.1)$ & \\
\hline 7 & $97(27.2)$ & $30(21.6)$ & $67(30.7)$ & \\
\hline $8-10$ & $39(10.9)$ & $19(13.7)$ & $20(9.2)$ & \\
\hline Clinical tumor stages** & & & & $<.001$ \\
\hline T1A/B & $46(12.9)$ & $29(20.9)$ & $17(7.8)$ & \\
\hline $\mathrm{T} 1 \mathrm{C}$ & $160(44.8)$ & $48(34.5)$ & $112(51.4)$ & \\
\hline $\mathrm{T} 2 \mathrm{~A}$ & $69(19.3)$ & $22(15.8)$ & $47(21.6)$ & \\
\hline T2B & $38(10.6)$ & $18(12.9)$ & $20(9.2)$ & \\
\hline $\mathrm{T} 2 \mathrm{C}$ & $22(6.2)$ & $14(10.1)$ & $8(3.7)$ & \\
\hline T3A/B & $22(6.2)$ & $8(5.8)$ & $14(6.4)$ & \\
\hline Risk groups (D'Amico) & & & & .071 \\
\hline Low & $146(40.9)$ & $51(36.7)$ & $95(43.6)$ & \\
\hline Intermediate & $124(34.7)$ & $45(32.4)$ & $79(36.2)$ & \\
\hline High & $87(24.4)$ & $43(30.9)$ & $44(20.2)$ & \\
\hline Prostate surgery & & & & $<.001$ \\
\hline Not performed & $64(17.9)$ & $38(27.3)$ & $26(11.9)$ & \\
\hline previous for BPH & $46(12.9)$ & $29(20.9)$ & $17(7.8)$ & \\
\hline synchronous with HIFU & $247(69.2)$ & $72(51.8)$ & $175(80.3)$ & \\
\hline $\mathbf{A D T}^{* * *}$ & & & & $<.001$ \\
\hline no & $244(68.4)$ & $72(51.8)$ & $172(78.9)$ & \\
\hline yes & $113(31.6)$ & $67(48.2)$ & $46(21.1)$ & \\
\hline \multicolumn{5}{|c|}{$\begin{array}{l}\text { Values are median (interquartile range) or N }(\%) \\
\text { *Device A1, Ablatherm Maxis }{ }^{\circledR} \text {; Device A2, Ablatherm Integrated Imaging }{ }^{\circledR} \\
\text { **TNM-classification } 2002 \\
\text { ***ADT, androgen deprivation therapy (preoperative) }\end{array}$} \\
\hline
\end{tabular}

Table 2. Treatment characteristics in 357 patients and in subgroups by Ablatherm HIFU devices

\begin{tabular}{|c|c|c|c|c|}
\hline & \multirow[t]{2}{*}{ Total } & \multicolumn{2}{|c|}{ Ablatherm HIFU devices } & \multirow[t]{2}{*}{ p value } \\
\hline & & Device A1* & Device A2* & \\
\hline Patients N (100\%) & 357 & 139 & 218 & \\
\hline \multicolumn{5}{|l|}{ Prostate volume on TRUS (mL) } \\
\hline at first visit & $28.6(20.6-38.0)$ & $23.0(17.0-31.0)$ & $32.0(24.1-41.0)$ & $<.001$ \\
\hline before HIFU [pre-plan] & $18(13-22)$ & $19(13-24)$ & $17(13-21)$ & .011 \\
\hline \multicolumn{5}{|l|}{ HIFU treatment data } \\
\hline Lesions per treatment (No.) & $586(501-668)$ & $629(505-759)$ & $566(501-645)$ & .001 \\
\hline Treatment volume $(\mathrm{mL})^{* *}$ & $37(31-43))$ & $40(32-50)$ & $36(30-40)$ & $<.001$ \\
\hline Treatment duration (min) & $145(125-170)$ & $165(135-200)$ & $135(120-155)$ & $<.001$ \\
\hline Treatment ratio*** & $2.1(1.7-2.5)$ & $2.1(1.6-2.8)$ & $2.1(1.8-2.4)$ & .447 \\
\hline \multicolumn{5}{|c|}{$\begin{array}{l}\text { Values are median (interquartile range) } \\
\text { *Device A1, Ablatherm Maxis }{ }^{\circledR} \text {; Device A2, Ablatherm Integrated Imaging } \\
\text { **Treatment volume, computed sum of single lesion volumes } \\
\text { ***Treatment ratio, treatment volume/TRUS-measured prostate volume [pre-plan] }\end{array}$} \\
\hline
\end{tabular}

The 10-year PCSS-rate was $95.0 \%(95-C I, 90-98 \%)$ (Figure 2). Nine (2.5\%) men died of PCa, including $3(2.4 \%)$ and 6 (7.0\%) patients in intermediate- and high-risk groups.

\section{Cancer control}

The median (IQR) nadir PSA was $0.04(0.02-0.16) \mathrm{ng} / \mathrm{mL}$, which occurred at $28.3(14.5-56)$ weeks. The nadir values in patients with previous ADT (0.04 [0.02-0.17] ng/ml) and men without (0.045 [0.02$0.16] \mathrm{ng} / \mathrm{ml})$ were similarly low $(\mathrm{p}=.61)$.

Control prostate biopsies were available for 215 (60.7\%) patients and were taken at a median (IQR) of 29.3 (23.7-62.5) weeks after HIFU, i.e near the time of PSA nadir. Biopsies were positive in 63 (29.3\%) men. Men with positive biopsies exhibited higher nadir PSA values (median [IQR], 0.3 [0.05-1.01]) than those with negative biopsies (0.03 [0.01$0.11])(\mathrm{p}<.001) .139$ (39.3\%) men with very low nadir PSA values $(0.03$ [0.02-0.09] $\mathrm{ng} / \mathrm{ml}$ ) omitted scheduled biopsy.

Biochemical relapse was recorded in 75 (21.2\%) and 100 (28.2\%) patients for nadir +2 or nadir +1.2 failure definitions. Table 3 shows the BDF-rates at 5 and 8 years. Depending on the failure definition, BFScalculation censored $30(48 \%)$ or $18(29 \%)$ of 62 men with local failure as non-failing, as they were transmitted to salvage therapy before PSA relapse occurred. 
Pfeiffer D (2021) Single application of high-intensity focused ultrasound (HIFU) in clinically localized prostate cancer- Late oncological results and comparative cancer control efficacy with different HIFU device generations

In total, $104(29.4 \%)$ men exhibited disease failure. First failure event was a positive biopsy in $62(59.6 \%)$ men and PSA progression to nadir+2 in another $42(40.4 \%)$. The overall 8 -year DFS-rate was $65 \%$ (95\%-CI,58-71\%). The 8-year DFS-rates in low-, intermediate-, and high-risk patients were $84 \%$ (75-91), 61\% (51-70) and $42 \%(30-$ $55)$, respectively $(\mathrm{p}<0.001)$ (Figure 3$)$. In the low- to intermediate-risk disease, treatment with the A2 device was more efficacious than with the older device (Table 4). Preoperative tumor determinants (PSA, Gleason sum, D'Amico risk category) and the HIFU device generation were univariate and multivariate risk factors of DFS, whereas clinical tumor stages and preoperative ADT were not (Table 5).
Metastases developed in 17 (4.8\%) patients and occurred in 14 men within 5 years after HIFU. The 10-year MFS-rate was 91\% (95\%-CI 8395\%) (Figure 4). High risk patients were exposed to an elevated risk of developing metastases (HR, 17.8 [95\%-CI, 2.29-138.6], $\mathrm{p}=0.006$ ). Lymph node involvement was present in six men and distant metastases were recorded in the remainder.

Salvage treatment was introduced to $85(24.0 \%)$ patients. $36(10.2 \%)$ men with persistent local tumor received therapy with curative intent, either repeat HIFU $(n=24)$, radiotherapy $(n=7)$, or prostatectomy $(n=5)$. $49(13.8 \%)$ comorbid men received only palliative ADT. Chemotherapy was initiated in $6(1.7 \%)$ men with metastases.

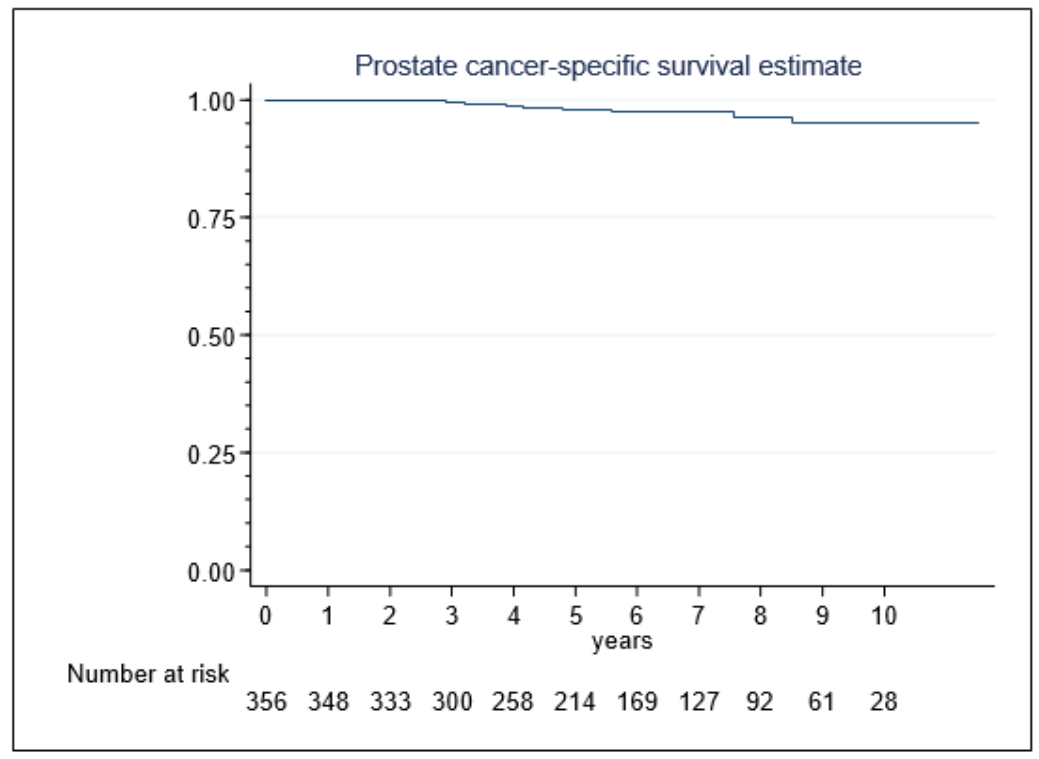

Figure 2. Prostate cancer-specific survival in 356 patients following single-session HIFU treatment of localized prostate cancer

Table 3. Biochemical failure-free survival probabilities in 354 patients according to Nadir +2 and Nadir +1.2 failure definitions, stratified by D'Amico risk groups

\begin{tabular}{|c|c|c|c|c|c|c|c|c|c|c|}
\hline \multirow[b]{4}{*}{ Variables } & \multicolumn{10}{|c|}{ Biochemical failure befinition } \\
\hline & \multicolumn{5}{|c|}{ Nadir+2 definition } & \multicolumn{5}{|c|}{ Nadir+1.2 definition } \\
\hline & \multicolumn{2}{|c|}{5 years } & \multicolumn{2}{|c|}{8 years } & p value & \multicolumn{2}{|c|}{5 years } & \multicolumn{2}{|c|}{8 years } & \multirow[t]{2}{*}{ p value } \\
\hline & $\begin{array}{l}\text { No. } \\
\text { at risk }\end{array}$ & $\hat{\mathrm{S}}(\mathrm{t})[95 \%-\mathrm{CI}]$ & $\begin{array}{l}\text { No. } \\
\text { at risk }\end{array}$ & $\hat{\mathrm{S}}(\mathrm{t})[95 \%-\mathrm{CI}]$ & & $\begin{array}{l}\text { No. } \\
\text { at risk }\end{array}$ & $\hat{\mathrm{S}}(\mathrm{t})[95 \%-\mathrm{CI}]$ & $\begin{array}{l}\text { No. } \\
\text { at risk }\end{array}$ & $\hat{\mathrm{S}}(\mathrm{t})[95 \%-\mathrm{CI}]$ & \\
\hline All cohort & 178 & $82 \%[77-86]$ & 67 & $74 \%[68-80]$ & & 159 & $73 \%[68-78]$ & 56 & $65 \%[58-71]$ & \\
\hline \multicolumn{11}{|c|}{ Risk groups (D'Amico) } \\
\hline Low & 84 & $98 \%([93-99]$ & 35 & $93 \%$ [83-97] & Ref. & 76 & $89 \%[82-94]$ & 29 & $81 \%[70-89]$ & Ref. \\
\hline Intermediate & 54 & $78 \%[68-84]$ & 19 & $76 \%[66-83]$ & .009 & 49 & $69 \%[59-77]$ & 16 & $62 \%[51-71]$ & .008 \\
\hline High & 40 & $62 \%([51-72]$ & 13 & $48 \%[35-60]$ & .001 & 34 & $54 \%[42-64]$ & 11 & $45 \%[33-57]$ & .002 \\
\hline
\end{tabular}

$\hat{\mathrm{S}}(\mathrm{t})[95 \%-\mathrm{CI}]=$ Estimated survival function in percentage with $95 \%$ confidence interval

Table 4. Disease failure-free survival probabilities according to the HIFU device generation, stratified by D'Amico risk groups

\begin{tabular}{|c|c|c|c|c|c|c|c|c|c|}
\hline \multirow[b]{4}{*}{ Variables } & \multicolumn{8}{|c|}{ HIFU device generation } & \multirow{4}{*}{ p value* } \\
\hline & \multicolumn{4}{|c|}{ HIFU device A1* $(n=136)$} & \multicolumn{4}{|c|}{ HIFU device A2* $(n=218)$} & \\
\hline & \multicolumn{2}{|c|}{5 years } & \multicolumn{2}{|c|}{8 years } & \multicolumn{2}{|c|}{5 years } & \multicolumn{2}{|c|}{8 years } & \\
\hline & $\begin{array}{l}\text { No. } \\
\text { at risk }\end{array}$ & $\hat{\mathrm{S}}(\mathrm{t})[95 \%-\mathrm{CI}]$ & $\begin{array}{l}\text { No. } \\
\text { at risk }\end{array}$ & $\hat{\mathrm{S}}(\mathrm{t})[95 \%-\mathrm{CI}]$ & $\begin{array}{l}\text { No. } \\
\text { at risk }\end{array}$ & $\hat{\mathrm{S}}(\mathrm{t})[95 \%-\mathrm{CI}]$ & $\begin{array}{l}\text { No. } \\
\text { at risk }\end{array}$ & $\hat{\mathrm{S}}(\mathrm{t})[95 \%-\mathrm{CI}]$ & \\
\hline All cohort & 71 & $62 \%[53-70]$ & 51 & $54 \%[45-62]$ & 85 & $81 \%[75-86]$ & 6 & $74 \%[65-81]$ & $<.001$ \\
\hline \multicolumn{10}{|c|}{ Risk groups (D'Amico) } \\
\hline Low & & $84 \%[70-92]$ & & $79 \%[64-88]$ & & $93 \%[85-97]$ & & $89 \%[75-95]$ & .092 \\
\hline Intermediate & & $49 \%[34-63]$ & & $47 \%[31-61]$ & & $76 \%[64-85]$ & & $73 \%[59-82]$ & .007 \\
\hline High & & $51 \%[35-65]$ & & $38 \%[22-53]$ & & $64 \%[45-77]$ & & $50 \%[31-67]$ & .360 \\
\hline \multicolumn{10}{|c|}{$\begin{array}{l}\hat{\mathrm{S}}(\mathrm{t})[95 \%-\mathrm{CI}]=\text { Estimated survival function in percentage with } 95 \% \text { confidence interval } \\
\text { * Device A1, Ablatherm Maxis }{ }^{\circledR} \text {; Device A2, Ablatherm Integrated Imaging }{ }^{\circledR} \\
\text { ** Device A1 vs. A2 }\end{array}$} \\
\hline
\end{tabular}


Pfeiffer D (2021) Single application of high-intensity focused ultrasound (HIFU) in clinically localized prostate cancer- Late oncological results and comparative cancer control efficacy with different HIFU device generations

Table 5. Univariate and multivariate analysis of disease-free survival

\begin{tabular}{|c|c|c|c|c|c|c|}
\hline \multirow[b]{2}{*}{ Variables } & \multicolumn{3}{|c|}{ Univariate analysis } & \multicolumn{3}{|c|}{ Multivariate analysis } \\
\hline & HR & $95 \%-C I$ & p value & HR & $95 \%-C I$ & p value \\
\hline PSA at diagnosis & 1.02 & $1.01-1.04$ & .001 & 1.02 & $1.01-1.03$ & $<.001$ \\
\hline Gleason sum & 1.25 & $1.01-1.55$ & .041 & 1.31 & $1.06-1.62$ & .013 \\
\hline $\begin{array}{l}\text { Clinical tumor stages* } \\
\text { T1-T2a } \\
\text { T2b } \\
\text { T2c-T3b }\end{array}$ & $\begin{array}{c}1 \\
1.43 \\
.69\end{array}$ & $\begin{array}{c}- \\
.81-2.53 \\
.36-1.31\end{array}$ & $\begin{array}{l}.211 \\
.254\end{array}$ & - & - & - \\
\hline $\begin{array}{l}\text { Risk groups (D'Amico) } \\
\text { Low } \\
\text { Intermediate } \\
\text { High }\end{array}$ & $\begin{array}{c}1 \\
2.16 \\
2.48\end{array}$ & $\begin{array}{c}- \\
1.15-4.07 \\
1.09-5.63\end{array}$ & $\begin{array}{l}.017 \\
.030\end{array}$ & $\begin{array}{c}1 \\
2.32 \\
2.03\end{array}$ & $\begin{array}{c}- \\
1.27-4.25 \\
.98-4.25\end{array}$ & $\begin{array}{l}.006 \\
.058\end{array}$ \\
\hline $\begin{array}{l}\text { ADT** } \\
\text { yes } \\
\text { no }\end{array}$ & $\begin{array}{c}1 \\
.93\end{array}$ & $.60-1.44$ & .736 & - & - & \\
\hline $\begin{array}{l}\text { HIFU device } \\
\text { A1 } \\
\text { A2 }\end{array}$ & $\begin{array}{c}1 \\
.51\end{array}$ & $.33-.79$ & .002 & $\begin{array}{c}1 \\
.51\end{array}$ & $.34-.78$ & .001 \\
\hline
\end{tabular}

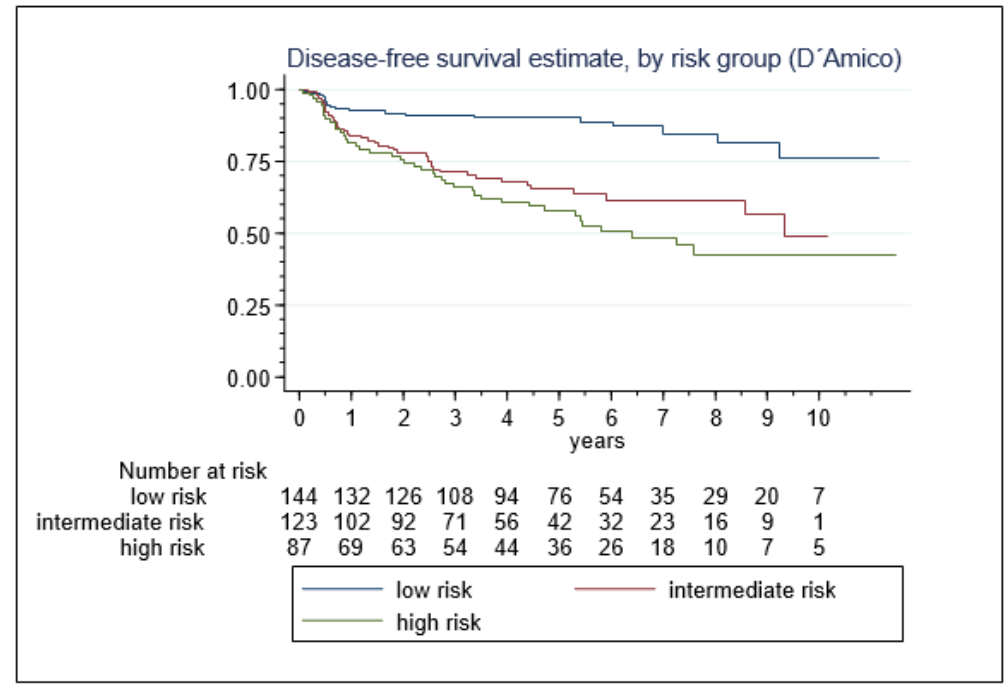

Figure 3. Disease-free survival in 354 patients following single-session HIFU treatment of localized prostate cancer, by D'Amico risk groups

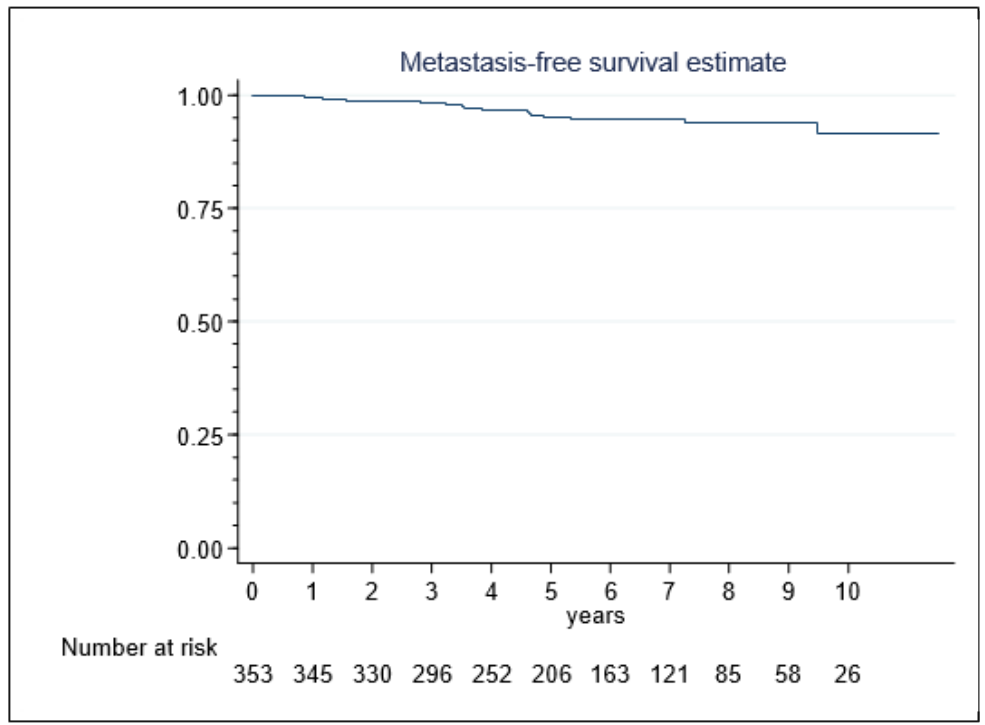

Figure 4. Metastasis-free survival in 353 patients following single-session HIFU treatment of localized prostate cancer 
Pfeiffer D (2021) Single application of high-intensity focused ultrasound (HIFU) in clinically localized prostate cancer- Late oncological results and comparative cancer control efficacy with different HIFU device generations

\section{Discussion}

The present study assessed late oncological outcomes following single-session HIFU treatment of localized PCa performed under the conception of whole-gland therapy. Differences to all previous reports concern the more extensive ablation technique, resulting in a higher volume ratio (treated/measured prostate volume) in this study (mean 2.2 vs. 1.3-1.9), and the more frequent use of the technically advanced A2 device (application rate $61 \%$ vs. $26-29 \%$ ) $[7,8]$.

In all, $84 \%$ of patients with low-risk disease attained a disease-free status at 8 years, with rates of cancer control declining in patients with intermediate- and high-risk disease. In a multivariate analysis, higher pre-treatment PSA values and biopsy Gleason scores were independent predictors of disease failure. In studies of radical prostatectomy, both variables were key factors for the risk of extra-prostatic disease extension [16]. Accordingly, the under-treatment of a considerable proportion of tumors in higher risk groups might reflect understaging prior to therapy.

However, the efficacy of HIFU was not solely dependent on tumor characteristics. Treatment proved to be more efficacious with the A2 HIFU device. The risk of disease failure decreased by approximately $50 \%$. The 8-year DFS-rates tend be higher in low-risk disease $(89 \%$ vs.79\%) and increased significantly in intermediate-risk disease $(73 \%$ vs. $47 \%$ ), while better outcomes in high-risk tumors ( $50 \%$ vs. $38 \%$ ) were not statistically significant.

These differences are remarkable, since the ablation technique was similarly extensive with both devices to ensure complete tumor eradication. A principal difference exists between the devices related to control facilities and the precision of the treatment conduct. With the A2 HIFU device a new electronic probe was introduced, which allowed visually directed ablation and a more accurate targeting of the prostate, thereby avoiding gaps between plan and performance and an under-treatment during therapy $[10,11]$. Our study suggests that these technological advances were associated with a greater efficacy of singlesession HIFU.

The composite definition of disease failure used in this study is based on positive biopsy or PSA progression to nadir $+2 \mathrm{ng} / \mathrm{ml}$. The biopsy execution rate of $61 \%$ compares to rates between $55 \%$ and $77 \%$ in other recent case-series $[7,8]$. Locally persistent tumor detected by scheduled biopsy near the time of PSA nadir was the primary event in $59.6 \%$ of men who failed, while the remainder eventually experienced PSA relapse without confirmation of local failure. This underlines the value of early post-HIFU biopsy especially if PSA nadir does not reach undetectable levels [17]. Presumably, treatment failure would have ultimately been recognized earlier if biopsies had been taken in all patients with rising PSA values. This is important if secondary curative treatment is intended, which provides more favorable clinical results before the PSA level rises to $>0.5 \mathrm{ng} / \mathrm{ml}$; such less pronounced rises in the PSA level imply smaller tumor foci which are difficult to detect by imaging [18].

Disease-free survival has also been reported according to strict biochemical failure definitions, either PSA progression to nadir+2 ng/ $\mathrm{ml}$, or to nadir+1.2 $\mathrm{ng} / \mathrm{ml}$ [15]. This study shows that both definitions are not very accurate for the calculation of disease-free rates, since men with early proven local failure, transmitted to salvage therapy before PSA relapse occurred, were misclassified as cured. Therefore, the composite disease failure definition may provide a more consistent picture of the cancer-control efficacy from single-session HIFU.
However, biochemical failure has been widely used as a measure of late oncological outcomes after HIFU treatment and most authors applied the nadir +2 definition originally designed to monitor biochemical response following RT [14].

Recently, Crouzet et al. reported 8-year multicenter outcomes in 1002 patients treated with Ablatherm HIFU. The median followup length $(6.4$ yrs.) corresponded to our study (6.5 yrs.). The BFSrates were $76 \%, 63 \%$, and $57 \%$ in low-, intermediate-, and high-risk disease, respectively. The study included results of repeated HIFU administrations with a mean of 1.4 treatments per patient, suggesting that in many patients a single HIFU ablation was not efficacious and complete tumor destruction required multiple treatments. The corresponding 8-year BFS-rates (nadir+2 definition) obtained in our study were $93 \%, 76 \%$ and $48 \%$, respectively. Accordingly, the biochemical cancer control rates with single-session HIFU were superior in low- and intermediate-risk disease, while patients with high-risk disease might marginally benefit from multiple treatments. Moreover, the MFS-rates (94\% vs. $91 \%$ ) and PCSS-rates (97\% vs. $95 \%$ ) at ten years were similar. In all, our data underline the curative potential of a single HIFU ablation, but also the limited efficacy to eradicate highrisk PCa.

Radiotherapy (RT) is an established primary treatment modality in elderly men [19]. With modern dose-escalated RT, Zumsteg et al. attained 8-year BFS-rates (nadir+2 definition) of 90.3\%, $77.3 \%$ and $57.1 \%$ in low-, intermediate-, and high-risk patients (IMRT, radiation dose $81 \mathrm{~Gy}$ ) [20]. Vora et al. reported 9-year BFS-rates of $77.4 \%, 69.9 \%$ and $53.3 \%$, respectively (IMRT, 75.6 Gy) [21]. Compared with singlesession HIFU, results from these studies indicate equivalent BFS-rates in low-risk and intermediate-risk disease and an additional benefit from RT in high-risk disease. The 10-year MFS-rates (95\%) and PCSSrates (96.2\%) reported by Alicikus et al. were similar [22]. However, whether a single application of HIFU represents a curative alternative to modern RT, applied over 4-6 weeks, requires long-term evaluation in prospective randomized trials or matched cohort studies.

We consider patients with low- to intermediate-risk disease as candidates for single-session HIFU treatment, whereas men with highrisk tumors are not treated safely even with whole-gland technique. Prostate size is not a limitation if prostate resection is considered as a part of the treatment protocol. Age $>75$ yrs. is not a contraindication, but treatment recommendation should be made cautiously in case of men with significant comorbidity.

Active surveillance (AS) is considered to be an alternative to interventional therapy in prostate tumors of low risk, even though these glands may harbor unfavorable pathology [23]. If the selection criteria for AS are limited to low-volume low-risk disease to minimize the risk of disease progression, active therapy remains an indication in patients with a more pronounced tumor burden and especially in those who experience disease progression under AS [19,23]. Whole-gland HIFU therapy is a valuable option for many of these men. Whether focal HIFU is a treatment alternative in low or intermediate risk disease, remains to be determined.

There are inherent limitations in this study, including its retrospective nature and design as a single arm study without control group. The data reflect single-center experience and may not be generally applicable. The median follow-up was only 6.5 years a length of time during which most prostate cancers are unlikely to result in metastatic spread or mortality. 
Pfeiffer D (2021) Single application of high-intensity focused ultrasound (HIFU) in clinically localized prostate cancer- Late oncological results and comparative cancer control efficacy with different HIFU device generations

\section{Conclusions}

The curative potential of single-session whole-gland therapy with HIFU has improved due to technological advances. Candidates for treatment are patients with organ-confined low- to intermediate-risk PCa.

\section{Conflict of interest}

Dietrich Pfeiffer acted as a trainer for EDAP-TMS.

\section{References}

1. Madersbacher S, Pedevilla M, Vingers L (1995) Effect of high-intensity focused ultrasound on human prostate cancer in vivo. Cancer Res 55: 3346.

2. Gelet A, Chapelon JY, Bouvier R (1996) Treatment of prostate cancer with transrectal focused ultrasound: early clinical experience. Eur Urol 29: 174. [Crossref]

3. Thüroff S, Chaussy C, Vallancien G (2003) High-intensity focused ultrasound and localized prostate cancer: efficacy results from the European multcentric study. $J$ Endourol 17: 673. [Crossref]

4. Uchida T, Ohkusa H, Nagata Y (2006) Treatment of localized prostate cancer using high-intensity focused ultrasound. BJU Int 97: 56.

5. D'Amico AV, Whittington R, Malkowicz SB (1998) Biochemical outcome after radical prostatectomy, external beam radiation therapy, or interstitial radiation therapy for clinically localized prostate cancer. JAMA 280: 969

6. Thüroff S, Chaussy C (2013) Evolution and outcomes of $3 \mathrm{MHz}$ high-intensity focused ultrasound for localized prostate cancer during 15 years. J Urol 190: 702.

7. Crouzet $\mathrm{S}$, Chapelon JY, Rouvière $\mathrm{O}$ (2014) Whole-gland ablation of localized prostate cancer with high-intensity focused ultrasound: Oncologic outcomes and morbidity in 1002 patients. Eur Urol 65: 907.

8. Ganzer R, Fritsche HM, Brandtner (2013) Fourteen-year oncological and functional outcomes of high-intensity focused ultrasound in localized prostate cancer. BJU Int 112: 322 .

9. Blana A, Robertson CN, Brown SCW (2012) Complete high-intensity focused ultrasound in prostate cancer: outcome from the @-registry. Prostate Cancer Prostatic Dis 15: 256.

10. Pichardo S, Gelet A, Curiel L (2008) New integrated imaging high intensity focused ultrasound probe for transrectal prostate cancer treatment. Ultrasound Med Biol 34: 1105 .
11. Cordeiro ER, Cathelineau X, Thüroff S (2012) High-intensity focused ultrasound (HIFU) for definitive treatment of prostate cancer. BJU Int 110: 1228.

12. Pfeiffer D, Berger J, Gross AJ (2012) Single application of high-intensity focused ultrasound as a first-line therapy for clinically localized prostate cancer: 5 -yr outcomes. BJU Int 110: 1702.

13. Ward JF, Stephen Jones J (2010) Classification system: organ preserving treatment for prostate cancer. Urology 75: 1258.

14. Roach M, Hanks G, Thames jr. H (2006) Defining biochemical failure following radiation therapy with or without hormonal therapy in men with clinically localized prostate cancer: recommendation of the RTOG-ASTRO Phoenix Consensus Conference. Int J Radiat Oncol Biol Phys 65: 965. [Crossref]

15. Blana A, Brown SC, Chaussy C (2009) High-intensity focused ultrasound for prostate cancer: comparative definitions of biochemical failure. BJU Int 104: 1058

16. Grossfeld GD, Chang JJ, Broering JM (2001) Under staging and under grading in a contemporary series of patients undergoing radical prostatectomy: results from the cancer of the prostate strategic urologic research endeavour database. J Urol 165: 851.

17. Ganzer R, Robertson CN, Ward JF (2011) Correlation of prostate-specific antigen nadir and biochemical failure after high-intensity focused ultrasound of localized prostate cancer based on the Stuttgart failure criteria - analysis from the @-registry. BJU Int 108: 196.

18. Cornford P, Bellmunt J, Bolla M (2017) EAU-ESTRO-SIOG Guidelines on prostate cancer. Part II: Treatment of relapsing, metastatic, and castration-resistant prostate cancer. Eur Urol 71: 630

19. Mottet N, Bellmunt J, Bolla M (2017) EAU-ESTRO-SIOG Guidelines on prostate cancer. Part 1: Screening, diagnosis, and local treatment with curative intent. Eur Urol 71: 618 .

20. Zumsteg ZS, Spratt DE, Romesser PB (2015) The natural history and predictors of outcome following biochemical relapse in the dose escalation era for prostate cancer patients undergoing definitive external beam radiotherapy. Eur Urol 67: 1009. [Crossref]

21. Vora SA, Wong WW, Schild SE (2013) Outcome and toxicity for patients treated with intensity modulated radiation therapy for localized prostate cancer. J Urol 2013 190: 521.

22. Alicikus ZA, Yamada Y, Zhang Z (2011) Ten-year outcomes of high-dose, intensitymodulated radiotherapy for localized prostate cancer. Cancer 117: 1429.

23. Moschini M, Carroll PR, Eggener SE (2017) Low-risk prostate cancer: identification, management, and outcomes. EUR Urol 72: 238.

Copyright: (C2021 Pfeiffer D. This is an open-access article distributed under the terms of the Creative Commons Attribution License, which permits unrestricted use, distribution, and reproduction in any medium, provided the original author and source are credited. 